\title{
Assessment of vector/host contact: comparison of animal-baited traps and UV-light/suction trap for collecting Culicoides biting midges (Diptera: Ceratopogonidae), vectors of Orbiviruses
}

\author{
Elvina Viennet ${ }^{1 *}$, Claire Garros ${ }^{1}$, Renaud Lancelot ${ }^{1}$, Xavier Allène ${ }^{1}$, Laëtitia Gardès' ${ }^{1}$ Ignace Rakotoarivony ${ }^{1}$,
} Didier Crochet ${ }^{2}$, Jean-Claude Delécolle ${ }^{3}$, Catherine Moulia ${ }^{4}$, Thierry Baldet ${ }^{1}$ and Thomas Balenghien ${ }^{1 *}$

\begin{abstract}
Background: The emergence and massive spread of bluetongue in Western Europe during 2006-2008 had disastrous consequences for sheep and cattle production and confirmed the ability of Palaearctic Culicoides (Diptera: Ceratopogonidae) to transmit the virus. Some aspects of Culicoides ecology, especially host-seeking and feeding behaviors, remain insufficiently described due to the difficulty of collecting them directly on a bait animal, the most reliable method to evaluate biting rates.

Our aim was to compare typical animal-baited traps (drop trap and direct aspiration) to both a new sticky cover trap and a UV-light/suction trap (the most commonly used method to collect Culicoides).

Methods/results: Collections were made from 1.45 hours before sunset to 1.45 hours after sunset in June/July 2009 at an experimental sheep farm (INRA, Nouzilly, Western France), with 3 replicates of a 4 sites $\times 4$ traps randomized Latin square using one sheep per site. Collected Culicoides individuals were sorted morphologically to species, sex and physiological stages for females. Sibling species were identified using a molecular assay. A total of 534 Culicoides belonging to 17 species was collected. Abundance was maximal in the drop trap (232 females and 4 males from 10 species) whereas the diversity was the highest in the UV-light/suction trap (136 females and 5 males from 15 species). Significant between-trap differences abundance and parity rates were observed.
\end{abstract}

Conclusions: Only the direct aspiration collected exclusively host-seeking females, despite a concern that human manipulation may influence estimation of the biting rate. The sticky cover trap assessed accurately the biting rate of abundant species even if it might act as an interception trap. The drop trap collected the highest abundance of Culicoides and may have caught individuals not attracted by sheep but by its structure. Finally, abundances obtained using the UV-light/suction trap did not estimate accurately Culicoides biting rate.

\section{Background}

Culicoides biting midges (Diptera: Ceratopogonidae) are among the smallest hematophagous insects and a pest to livestock and humans [1]. They also can transmit several important Orbivirus (Reoviridae) such as African horse sickness virus to equids or bluetongue virus (BTV) to ruminants [1]. Bluetongue was considered an exotic disease in Europe until the spread of multiple

\footnotetext{
* Correspondence: elvina.viennet@cirad.fr; thomas.balenghien@cirad.fr ${ }^{1}$ CIRAD, UMR Contrôle des maladies, F-34398 Montpellier, France Full list of author information is available at the end of the article
}

BTV strains throughout the Mediterranean Basin from 1998 to the present day, mainly in association with the presence of Culicoides imicola Kieffer, the main Afrotropical vector species [2]. During 2006, a BTV8 epizootic occurred in five member states of north-western Europe in the absence of C. imicola confirming that some autochthonous Palaearctic Culicoides species are able to transmit BTV [3]. However, the virus quickly spread to other countries in the following years infecting a surprising number of farms through Europe (for instance about 27,000 BTV8 and 5,000 BTV1 outbreaks in the French mainland in 2008) leading to disastrous 
consequences for the livestock industry with huge economic losses [4].

Many aspects of Culicoides ecology remain unknown especially for species suspected to be involved in BTV8 transmission in Europe [1,5]. Their host-seeking and feeding behaviors are poorly described partially because of the difficulty in collecting these small insects directly on animals. Direct collection from animals is considered the most reliable method to study the vector/host ratio [6], an essential parameter to model vectorial capacity and virus transmission [7]. Only a few collections of Palaearctic Culicoides have been carried out directly on hosts [8-13]. Direct aspiration and drop trap, the most common host-baited collection, have been compared to artificially baited traps especially the ultraviolet (UV) light/suction trap [12,13], which is the most widespread method to collect Culicoides. UV-light/suction traps seemed to underestimate biting rates of Culicoides chiopterus (Meigen) [12], Culicoides obsoletus (Meigen) and Culicoides parroti Kieffer [13] and to overestimate the biting rate of C. imicola [13] on sheep. However host-baited traps have never been compared with each other, or simultaneously to a light trap.

The aim of this study was to improve our ability to accurately describe the Culicoides ecology by identifying the best trapping assessment of the vector biodiversity and the biting rate in north-western Europe. We compared standard animal-baited traps (drop trap and direct aspiration), to a novel trapping system which utilized sticky panels and to a UV-light/suction trap commonly used in Culicoides surveillance.

\section{Materials and methods}

Our strategy was to use a randomized Latin square design to compare the assessment of the biting rate by each animal-baited trap and to identify potential bias when UV-light/suction trapping might be used to estimate the biting rate.

\section{Description of collection methods}

Four collection methods were compared during this trial (Figure 1).

The drop trap (DT) consists in a rectangular cage in shape ( $2.5 \mathrm{~m}$ wide $\times 3 \mathrm{~m}$ long and $2 \mathrm{~m}$ high) recovered with white polyester netting $\left(<0.25 \mathrm{~mm}^{2}\right.$ mesh size $)$ [12]. Initially, a single sheep is exposed for $10 \mathrm{~min}$ with the netted sides of the cage raised and the observer remaining at a distance of approximately $50 \mathrm{~m}$ from the trap. Thereafter, the observer returns to lower the net, making sure that no insect can enter or escape, and left the site for another $10 \mathrm{~min}$. Then, the observer entered the netted cage and vacuums the 4 sides plus the roof for about 10 min using a modified CDC Backpack aspirator (model 1412, John W. Hock company, http://

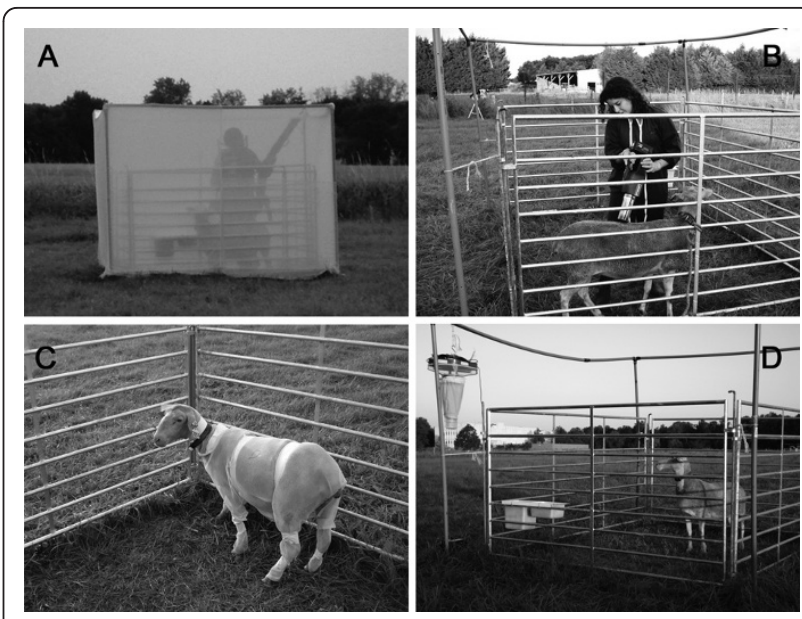

Figure 1 Four collection methods compared during 12 days using a $4 \times 4$ Latin square design: (A) drop trap, (B) direct aspiration, (C) sticky cover trap and (D) UV-light/suction trap (OVI)

www.johnwhock.com) with fine mesh cups (adapted to biting midges with $<0.25 \mathrm{~mm}^{2}$ mesh size) to collect any Culicoides present. On completion of this period, the drop net is raised for an additional 10 min exposure period.

The second type of animal-baited trap assessed consisted in direct aspiration (DA) on an animal. A single sheep tethered to a cage was exposed for $10 \mathrm{~min}$ - the observer remaining at a distance of approximately $50 \mathrm{~m}$ from the animal. Then the observer vacuumed the animal using an aspirator (Heavy Duty Hand-Held Vac/ Aspirator \#2820GA by BioQuip Products Inc., http:// www.bioquip.com) for $10 \mathrm{~min}$ (5 min to the upper part, from the nostrils to the tail limited by the line breastquarter, and $5 \mathrm{~min}$ to the lower part, down to the line breast-quarter; the part first vacuumed was alternatively the upper and the lower part). Both sides of the sheep were completely vacuumed. Then, an additional $10 \mathrm{~min}$ exposure period started.

A sticky cover trap (SCT) was also developed as a new host-baited collection method. Different adhesive products were tested on a white mosquito net of fiberglass $\left(1 \mathrm{~mm}^{2}\right.$ mesh size) for their ability to capture insects and to keep them in good condition for identification. According to the number and size of collected insects and the facility of removing and identifying them, petroleum jelly (Transgel $110^{\circledR}$ AIGLON S.A.) was preferred to glue, or oil as an adhesive. This product was still sticky after several hours of exposure. Thereafter, to the panels were fitted directly onto a sheep. A mosquito netting cover was subdivided into several body parts (back, belly/flank, head, and legs) to identify the landing zones. The cover was held down on the sheep by tape 
and coated by a thin layer of petroleum jelly. The sheep was then allowed to move freely within the pen during each evening experiment without any human interference. At the end of the exposure period, the sticky cover was cut off carefully according to the defined body parts. Culicoides were then carefully removed using a paintbrush dipped in clean engine oil to dilute petroleum jelly.

We compared these host-baited traps to a UV-light/ suction trap (OVI) manufactured by the Onderstepoort veterinary institute (South Africa) [14]. This trap is equipped with an 8-W UV light tube and a downdraft suction motor ended by a plastic beaker containing a drop of soap in water. It was operated with a 12 -volt car battery and placed at $1.5 \mathrm{~m}$ height from the ground on the cage where a single sheep was present.

\section{Study site and procedure of trap comparison}

Trap comparisons were conducted over 12 days from the $11^{\text {th }}$ June to $13^{\text {th }}$ July 2009 (a seasonally favorable period for Culicoides diversity and abundance in western France) on an experimental farm (Institut National de la Recherche Agronomique, INRA, UE1277 PFIE) breeding sheep and dairy cattle at Nouzilly $\left(47^{\circ} 33^{\prime} 01^{\prime \prime} \mathrm{N} ; 00^{\circ}\right.$ $47^{\prime} 52$ "'E; western France). Four sites were designated in the field surrounded by two grazing sheep herds (10 ewes and 20 rams close to the site 2), by grazing cattle herds (10 to 20 Holstein-Friesians heifers) and by dairy/ sheep holding $(<150 \mathrm{~m}$ ) (Figure 2). Designated sampling sites were separated by $50 \mathrm{~m}$ to minimize interference between traps.

Traps were compared using a $4 \times 4$ Latin square design, replicated 3 times. Each trap was randomly assigned to a site for the first collection evening. Then, random assignation was repeated the next three evenings with the condition that traps should be assigned to a different site each collection. Assignation procedure was repeated independently for each replicate. All collections were started and stopped $1 \mathrm{~h} 45$ before and after the sunset (3.5 hours of collection around sunset).

Six south-Prealpes female sheep were separated into two groups. They were about 6 years old, $50-\mathrm{kg}$ live weight and shorn three weeks before the experimentation began. One group was assigned to the sticky cover trap to avoid that residual petroleum jelly on sheep, which could alter results when used in another treatment. In this group, one animal was randomly chosen for each collection day and was cleaned up with a shedding blade after each experiment. In the other group, all animals were randomly assigned to a given treatment to avoid potential individual sheep effects. Each protocol step was conducted with respect to the standard ethical rules (staff was qualified for animal experimentation, premises are licensed for experiment, protocol

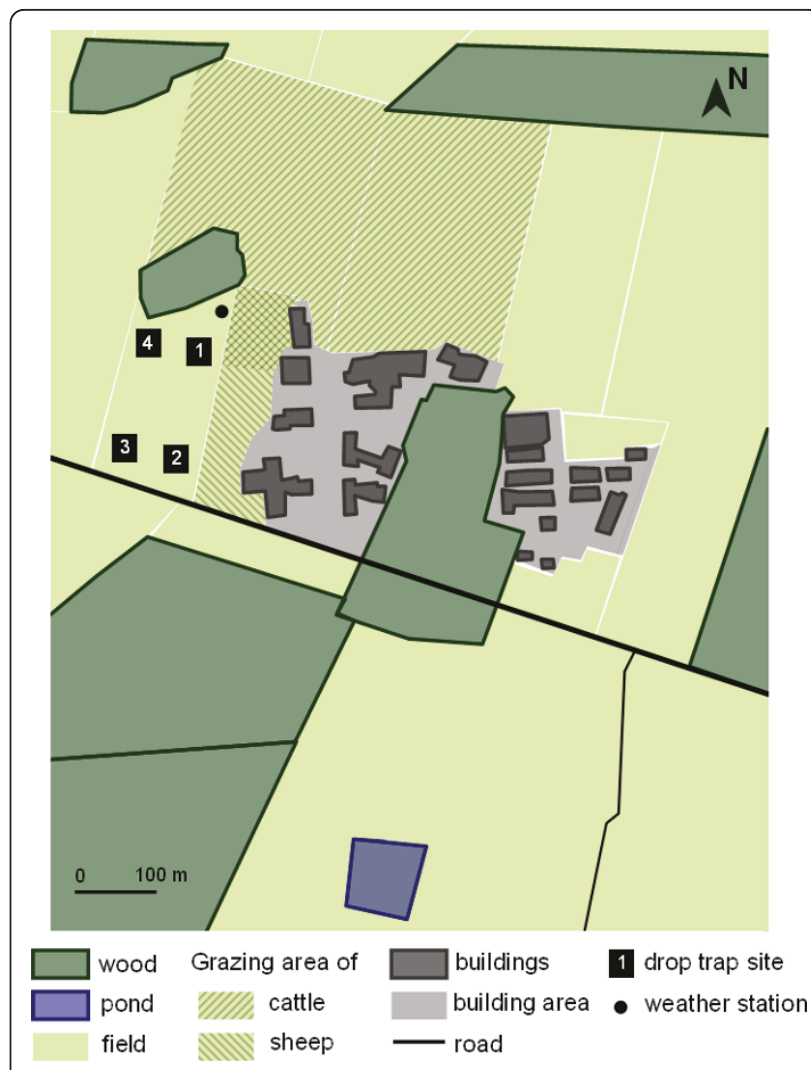

Figure 2 Sketch map of the study site (Inra) at Nouzilly (western France).

procedure does not cause any pain (no injection, no biological sample, no surgery)).

Meteorological conditions (air temperature, wind speed and direction, relative humidity and rainfall) were recorded every fifteen minutes using a weather station Vantage Pro 2 (Davis Instruments France, http://www. davis-meteo.com) situated close to the traps (Figure 2). To prevent the drop net from tearing away and to protect the animals, experiments were stopped or cancelled when wind speed was higher than $8.5 \mathrm{~m} / \mathrm{s}$ or when heavy rain disrupted operation of the drop trap. Monthly meteorological data recorded by national weather station (Météo France) at Parcay-Meslay ( $47^{\circ}$ $26^{\prime} 36^{\prime \prime} \mathrm{N}$; 00 $43^{\prime} 36^{\prime \prime} \mathrm{E} ; 13 \mathrm{~km}$ from the study site) in 2009 and from 1971 to 2000 were compared to illustrate meteorological conditions during the year of collections.

\section{Culicoides identification}

After captures, collection cups from drop trap and direct aspiration were stored at $-20{ }^{\circ} \mathrm{C}$ overnight to kill insects. Culicoides collected from sticky cover trap were stored in engine oil. The insects collected with the UV-light/suction trap were stored in $70 \%$ ethanol. All Culicoides were morphologically identified under a 
stereomicroscope (Stemi 2000C ZEISS) to species level based on identification key for the Palaearctic region [15] and sorted by sex. Females were classified as nulliparous, parous [16], freshly blood-fed and gravid. When morphological identification with stereomicroscope was not possible, individuals were dissected and identified using microscopic slide preparations (ZEISS imager A.1 fluorescence microscope).

All individuals identified as belonging to the Obsoletus Group (C. chiopterus, Culicoides dewulfi Goetghebuer, C. obsoletus and Culicoides scoticus Downes \& Kettle) were molecularly confirmed and identified following the assay developed by Nolan et al. [17] including primers for these four species. Genomic DNA was extracted from individual midges using Chelex resin $(50 \mu \mathrm{L} / \mathrm{Culi}$ coides) [18]. Primers and PCR amplifications conditions were as described by Nolan et al. [17]. Different preliminary tests were made before the start of collections to check the efficiency of the molecular assay on Culicoides collected through petroleum jelly and engine oil. Briefly, DNA extraction and PCR amplifications were carried out on two individuals kept in (i) petroleum jelly, (ii) engine oil, with and without a cleaning step before DNA extraction. Finally, prior to DNA extraction with Chelex resin, these Culicoides were individually cleaned on absorbent paper, followed by soapy water, rinsed twice in purified water, and dried on paper towel. We identified molecularly the origin of blood-meals of 45 engorged females randomly sampled in drop trap and direct aspiration collections at different collection dates. The aim was to confirm that they had fed on the bait animals. Primers and PCR conditions were as described by Garros et al.[19].

\section{Statistical analysis}

We compared the number of Culicoides females and their parity rate (proportion of parous females per collection) between traps. Exposure periods differed between traps $(3 \times 10 \mathrm{~min}$ for DA, $2 \times 10 \mathrm{~min}$ for DT, $1 \times 60 \mathrm{~min}$ for OVI and SCT during one hour). We assumed that Culicoides attracted to bait remained in the vicinity of the drop trap outside the exposure period and that some Culicoides remained attracted by the bait during the direct aspiration period. Thus, we did not correct the data and compared the biting rate assessed by operating each method during a given period (here 3.5 hours). For plotting, abundance data were $\log _{\mathrm{e}}(\mathrm{n}+$ 1) transformed to limit the overwriting of some points by high values. For analysis, we used untransformed abundance data.

Data were modeled using a Poisson mixed model for abundance data of dominant species, and a Binomial mixed model for parity rates of all species [20]. Capture date and site were the crossed random effects and trap was the fixed effect. However, exploratory analysis revealed an excess of zeros with respect to a Poisson distribution in abundance data for minor species. For these species the counts were analyzed using the socalled Hurdle model to model the counts [21,22]. The Hurdle model has two components: (i) a truncated count component (Poisson regression model) was used for counts $>0$, and (ii) a hurdle component modeled zero vs. larger counts (binomial regression model). Date and site effects were left in the residual variance.

Predicted values were plotted against observed counts to assess model goodness of fit. Cook's distance was used to detect influential observations [23]. For comparisons of trap effects, Wald tests were used together with Holm's $p$-value adjustment for multiple comparisons ( $\alpha$ $=0.05)$. On some occasions, when the fitted probabilities are close to zero, the Wald test may give unreliable results [24]. It was the case for species of low abundance. To overcome this problem, we used a graphical procedure [25] ensuring that non- overlapping confidence intervals indicated significant statistical differences. For these particular situations, which corresponded to cases of excess of zero, we simply gave the lowest $\mathrm{p}$-value for which a difference in abundance between trap types was observed (if this p-value remained compatible with an acceptable primary risk, $i$. e. $\alpha$ close to 0.1 ).

Using direct aspiration and the sticky cover trap, we collected Culicoides by body region: upper and lower parts for direct aspiration and back, head, belly and legs for sticky cover trap. Upper part versus lower part in the direct aspiration and back/head versus belly/legs in the sticky cover trap were compared for the five most abundant species using the chi-squared test $(\alpha=0.05)$. For these species, we explored the variability of their hostseeking activity around sunset as regular collections were made using direct aspiration (10 min by each 20 min period) and drop trap (10 min by each $30 \mathrm{~min}$ period).

All data analyses were performed using the $\mathrm{R}$ statistical package [26].

\section{Results}

\section{Climatic data}

Climate in the study site was oceanic, with mean annual temperature of $11.4^{\circ} \mathrm{C}$, thermal amplitude of $14.9^{\circ} \mathrm{C}$ and annual rainfall of $694 \mathrm{~mm}$ (Météo France data, 19712000). The year 2009 was a standard year in terms of meteorology except a slight water deficit in spring (195 mm between February and May 2009 versus 234 mm for the reference period) and a dry month of August (3 $\mathrm{mm}$ versus $40 \mathrm{~mm}$ ). Due to technical problems, complete meteorological data sets were available only for 9 of 12 sunset collection periods. During these collection 
days, wind was mainly oriented to northwest and southeast, with maximum speed of $4.5 \mathrm{~m} / \mathrm{s}$ and no rainfall was recorded. Collections were carried out with temperatures between 12.5 and $29.5^{\circ} \mathrm{C}$ and humidity between 45 and $95 \%$.

\section{Collection data}

During the 12 collection carried out around sunset, a total of 534 Culicoides (525 females and 9 males) belonging to 17 species were collected (Table 1). It was not possible to morphologically identify 2 damaged specimens which were recorded as Culicoides sp. Molecular assay confirmed morphological identification and separated sibling species for $88 / 90$ individual from the Obsoletus Group (i.e. C. obsoletus, C. scoticus, C. dewulfi and C. chiopterus). It was not possible to identify 2 individuals from the Obsoletus Complex (i.e. C. obsoletus and C. scoticus).

In total, 232 females (44\% of total catch) were collected with the drop trap, $136(26 \%)$ by the UV-light/ suction trap, $83(16 \%)$ by the sticky cover trap and 74 (14\%) by direct aspiration (Table 1). Among the hostbaited traps, the sticky cover trap and the direct aspiration collected approximately the same number of species (7 with SCT and 6 with DA), whereas the drop trap collected 10 different species. The UV-light/suction trap collected 15 different species, of which Culicoides circumscriptus Kieffer, Culicoides shaklawensis Khalaf, Culicoides simulator Edwards, Culicoides santonicus Callot, Kremer, Rault \& Bach or Culicoides clastrieri Callot, Kremer \& Deduit were not collected with the other traps. The log abundance of the total number of females for each species was linearly correlated with the species rank $\left(R^{2}=0.97\right.$; data not shown), with Culicoides brunnicans Edwards being the dominant species. The same shape of log abundance by species rank was observed for all the traps $\left(R^{2}=0.86\right.$ for DT, 0.75 for DA and 0.76 for OVI), except for the sticky cover trap $\left(R^{2}=0.51\right)$ due to the absence of $C$. obsoletus and the scarcity of $C$. dewulfi (Table 1). The Shannon-Wiener $(H)$ and the Simpson-Yule $(D)$ indices confirmed these differences: i) good correspondence between indices for the total number of females collected $(H=1.44$ and $D=0.39)$, for drop trap $(H=1.22$ and $D=0.46)$ and for direct aspiration $(H=1.42$ and $D=0.31)$, ii) deviance with the sticky cover trap $(H=0.70$ and $D=0.71)$ due to the underrepresentation of $C$. obsoletus and $C$. dewulfi, and iii) deviance with the UV-light/suction trap $(H=1.70$ and $D=0.27$ ) due to the under-representation of $C$. dewulfi and the over-representation of Culicoides punctatus (Meigen) and Culicoides achrayi Kettle \& Lawson (Table 1).

Males were collected only by the drop trap and the UV-light/suction trap, and gravid females only by the sticky cover trap and the UV-light/suction trap (Table $1)$. Almost all engorged females were caught by the drop trap (70 vs. 4 by DA, 2 by SCT and 1 by OVI). We tested 44 blood-fed females (29 C. brunnicans, $14 \mathrm{C}$. obsoletus and 1 C. scoticus) of the 70 collected in the drop trap and 1 C. brunnicans of the 4 collected in the direct aspiration. All engorged females had fed on sheep except 2 C. brunnicans for which blood-meal origin was not identified. No blood engorged $C$. dewulfi was found, though it was the second dominant species in drop trap.

\section{Trap comparison}

The abundance of C. brunnicans, the dominant species, varied considerably between days (Figure 3A). Abundance of C. brunnicans and of other Culicoides species at the sites used during the studies varied (Figures 3A \&3B), suggesting an impact of available larval habitat and suitable adult resting areas.

Abundance data for C. brunnicans were correctly predicted with the Poisson mixed model $\left(R^{2}=0.98\right.$; Figure $3 C)$. The same applied to the Hurdle model for $C$. dewulfi, C. scoticus and C. punctatus. Poor model predictions were obtained for C. obsoletus. Cook's distances showed influential values for site 2 where most C. brunnicans were collected and for site 4 where this species was nearly absent (Figure 3D). However, this variability was far more important for dates: the $11^{\text {th }}$ June recorded the highest abundance of C. brunnicans (Figure 3D), and the $6^{\text {th }}, 8^{\text {th }}$ and $13^{\text {th }}$ the lowest abundances.

Both drop trap and sticky cover trap collected more $C$. brunnicans than the UV-light/suction trap whereas the direct aspiration was the less efficient method $(p<0.05)$ (Table 2). For other species, Wald test procedure gave unreliable results, i.e. p-values tend to 0 or 1 , due to the low value of fitted probabilities [24,27]. Using the graphical procedure, differences were observed between traps for $C$. obsoletus abundance $(p=0.13)$ : in positive collections, the UV-light/suction trap collected more C. obsoletus than drop trap or direct aspiration. It was not possible to establish differences between traps for $C$. dewulfi even if predicted abundances in positive collections were higher with the drop trap or the direct aspiration than with the UV-light/suction trap. Using graphical procedures, differences in predicted abundances were observed in positive collections for C. scoticus between sticky cover trap (the highest predicted abundance) and direct aspiration (the lowest) $(p=0.13)$. Finally, no between-trap difference was observed for C. punctatus.

The parity rate of $C$. brunnicans was higher in the UV-light/suction trap than in the host-baited traps $(0.72$ versus less than $0.65, \mathrm{p}<0.05$ ) (Table 3 ). Parity rate of C. obsoletus was greater in the drop trap (0.86) than in UV-light/suction trap $(0.54, \mathrm{p}<0.017)$ and in direct aspiration (0.86 in DT versus 0.54 in OVI and 0.41 in 
Table 1 Numbers of Culicoides collected over 12 nights using four trapping methods Species $^{1} \quad$ Total No. Rank species

No. Culicoides collected with

\begin{tabular}{|c|c|c|c|c|c|c|c|c|c|c|c|c|c|c|c|c|c|c|c|}
\hline & & \multirow[t]{2}{*}{ 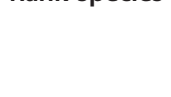 } & \multicolumn{4}{|c|}{ Drop trap ${ }^{2}$} & \multicolumn{3}{|c|}{ Direct aspiration } & \multicolumn{4}{|c|}{ Sticky cover trap } & \multicolumn{5}{|c|}{ UV-light/suction trap } \\
\hline & $\mathbf{F}$ & M & & No. $F$ & Parity & No. $E$ & No. M & No. $F$ & Parity & No. $\mathrm{E}$ & No. $F$ & Parity & No. E & No. G & No. $F$ & Parity & No. E & No. G & No. $M$ \\
\hline C. brunnicans & 313 & 6 & 1 & 153 & 0.48 & 49 & 4 & 36 & 0.69 & 1 & 69 & 0.39 & & 7 & 55 & 0.67 & & & 2 \\
\hline C. obsoletus & 75 & & 2 & 22 & 0.86 & 15 & & 14 & 0.43 & 3 & & & & & 39 & 0.54 & & & \\
\hline C. dewulfi & 46 & 1 & 3 & 27 & 0.44 & & & 14 & 0.43 & & 1 & 1.00 & & & 4 & 0.25 & & & 1 \\
\hline C. scoticus & 27 & & 4 & 8 & 0.13 & 1 & & 5 & 0.40 & & 4 & 0.25 & & & 10 & 0.00 & & & \\
\hline C. punctatus & 16 & & 5 & 2 & 0.50 & & & & & & 3 & 1.00 & & 1 & 11 & 0.55 & & & \\
\hline C. vexans & 15 & & 6 & 9 & 0.89 & 3 & & 2 & 1.00 & & 3 & 1.00 & 2 & & 1 & 1.00 & & & \\
\hline C. achrayi & 10 & & 7 & 2 & 0.50 & 1 & & & & & 1 & 0 & & & 7 & 0.57 & 1 & 2 & \\
\hline C. chiopterus & 6 & & 8 & 2 & 0.00 & & & 2 & 1.00 & & 1 & 1.00 & & & 1 & 1.00 & & & \\
\hline C. subfasciipennis & 5 & & 9 & 5 & 0.80 & 1 & & & & & & & & & & & & & \\
\hline C. pulicaris & 2 & 1 & 10 & & & & & & & & & & & & 2 & 0.50 & & & 1 \\
\hline C. picturatus & 1 & & 11 & 1 & 1.00 & & & & & & & & & & & & & & \\
\hline C. circumscriptus & 1 & & 11 & & & & & & & & & & & & 1 & 1.00 & & & \\
\hline C. santonicus & 1 & & 11 & & & & & & & & & & & & 1 & 1.00 & & & \\
\hline C. shaklawensis & 1 & & 11 & & & & & & & & & & & & 1 & 1.00 & & 1 & \\
\hline C. simulator & 1 & & 11 & & & & & & & & & & & & 1 & 1.00 & & 1 & \\
\hline C. lupicaris & 1 & & 11 & & & & & & & & & & & & 1 & 0.00 & & & \\
\hline C. clastrieri & & 1 & 11 & & & & & & & & & & & & & & & & 1 \\
\hline Obsoletus Complex & 2 & & 11 & & & & & 1 & 1.00 & & & & & & 1 & 0.00 & & & \\
\hline Culicoides sp. & 2 & & & 1 & 0.00 & & & & & & 1 & 0.00 & & & & & & & \\
\hline Total & 525 & 9 & & 232 & & 70 & 4 & 74 & & 4 & 83 & & 2 & 8 & 136 & & 1 & 4 & 5 \\
\hline
\end{tabular}

${ }^{1}$ For the sake of clarity, 0 were not quoted.

${ }^{2}$ F: females; M: males; E: engorged; G: gravide. Parity rate is No. parous/No. females. 

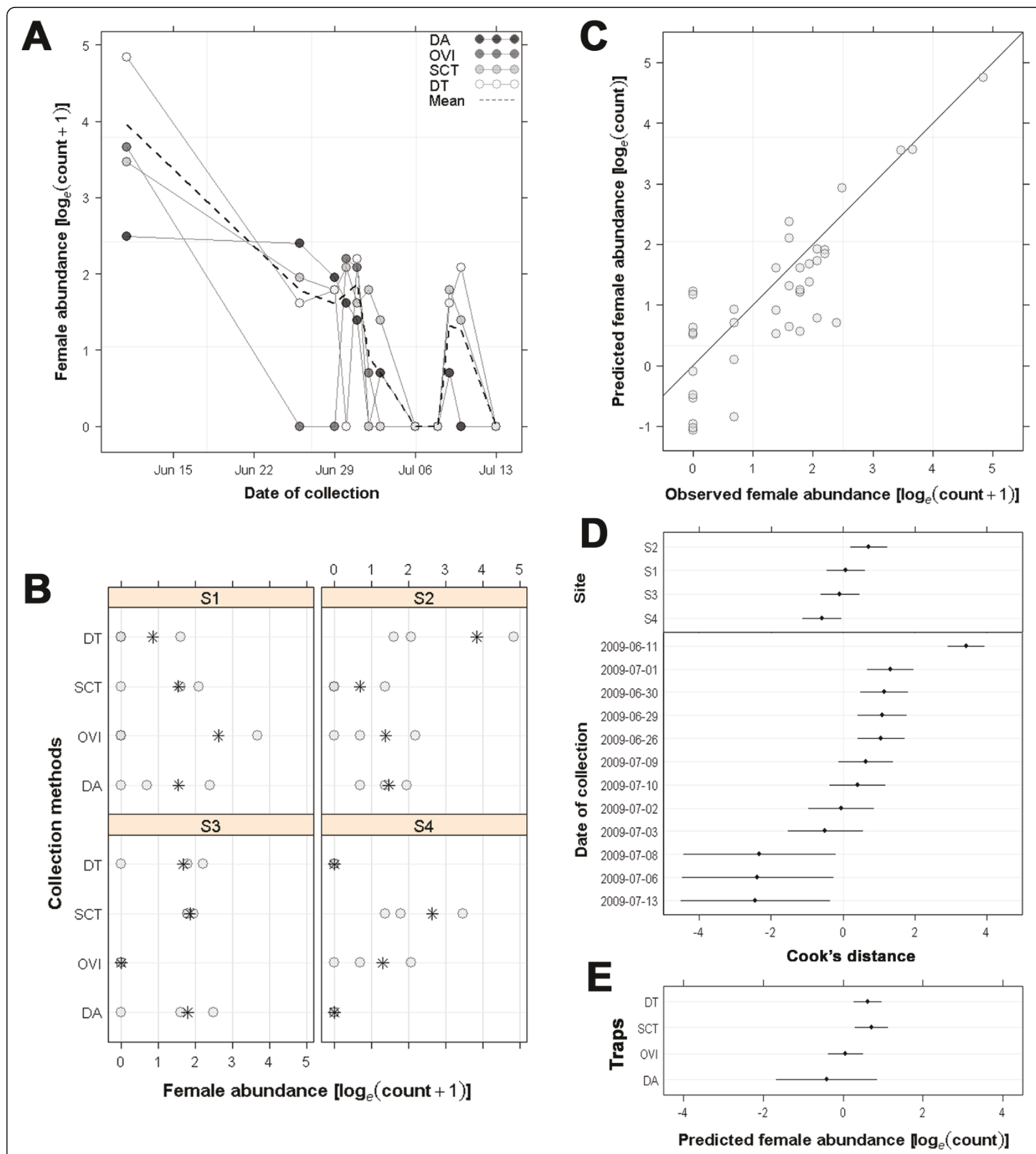

Figure 3 Graphical exploration of $\boldsymbol{C}$. brunnicans female collections: (A) daily abundance, (B) number of females collected by site and by trap, (C) predicted and observed abundances, (D) assessment of the random effects of dates and sites and (E) predicted abundances by trap. NB: abundances were plotted using a $\log _{e}$ scale. 
Table 2 Observed and predicted biting rates per collection session

\begin{tabular}{cccccccccccc}
\hline & \multicolumn{4}{c}{ Mean No. } & \multicolumn{5}{c}{ Predicted No. Q $^{2}$} \\
Species $^{1}$ & N & DT & DA & SCT & OVI & p & DT & DA & SCT & OVI \\
\hline C. & 313 & 12.8 & 3.0 & 5.8 & 4.6 & $<$ & $1.9^{\mathrm{a}}$ & $0.7^{\mathrm{b}}$ & $2.0^{\mathrm{a}}$ & $1.1^{\mathrm{c}}$ \\
brunnicans & & & & & & 0.05 & & & & \\
\hline C. obsoletus & 75 & 2.8 & 2.8 & - & 4.9 & $<$ & $2.5^{\mathrm{a}}$ & $2.6^{\mathrm{a}}$ & - & $4.8^{\mathrm{b}}$ \\
& & & & & & 0.13 & & & & \\
\hline C. dewulfi & 46 & 3.9 & 2.0 & 1.0 & 1.3 & - & 3.8 & 1.6 & - & 0.6 \\
\hline C. scoticus & 27 & 2.0 & 1.7 & 4.0 & 3.3 & $<$ & $1.6^{\mathrm{ab}}$ & $1.1^{\mathrm{b}}$ & $3.9^{\mathrm{a}}$ & $3.2^{\mathrm{ab}}$ \\
\hline C. punctatus & 16 & 2.0 & - & 3.0 & 1.8 & - & 1.6 & - & 2.8 & 1.4 \\
\hline
\end{tabular}

${ }^{1}$ Data correspond to number of females per collection for $C$. brunnicans and to number of females per positive collection for the other species

${ }^{2}$ Different letters mean difference between traps in predicted number of females with the given $p$-value using the Wald test procedure for $C$. brunnicans and the graphical procedure for other species

SCT, p < 0.05). Finally, the low number of C. punctatus females did not allow us to compare parity rates between traps.

\section{Preferential landing sites and circadian rhythm}

By direct aspiration, we collected $57 \%$ of the females on the upper part of sheep and using the sticky cover trap $45 \%$ on the upper part (back and head). Culicoides brunnicans seemed to attack indifferently upper and lower parts of animal (Figure 4, $p=0.2$ for DA and $p=0.9$ for SCT). Culicoides dewulfi attacked the upper parts of the animal preferentially ( $p<0.001$ for DA), whereas $C$. obsoletus was more abundant on lower parts $(p<0.05$ for DA). However, counts for both these species were relatively small limiting the generalization of these observations. Counts in other species were too small to highlight differences in attack zones (Figure 4).

All Culicoides captured in the study exhibited a peak in activity cycle shortly before dusk (Figure 5).

\section{Discussion}

This study has demonstrated for the first time that $C$. brunnicans can be present in substantial numbers on

Table 3 Observed and predicted parity rate per collection session

\begin{tabular}{lccccccccc}
\hline & \multicolumn{1}{c}{ Observed parity rate } & \multicolumn{3}{c}{ Predicted parity rate } \\
\multicolumn{1}{c}{ Species } & N & DT & DA & SCT & OVI & DT & DA & SCT & OVI \\
\hline C. brunnicans & 313 & 0.47 & 0.69 & 0.39 & 0.67 & $0.51^{\mathrm{a}}$ & $0.65^{\mathrm{a}}$ & $0.42^{\mathrm{a}}$ & $0.72^{\mathrm{b}}$ \\
\hline C. obsoletus & 75 & 0.86 & 0.43 & - & 0.54 & $0.86^{\mathrm{a}}$ & $0.41^{\mathrm{b}}$ & - & $0.54^{\mathrm{b}}$ \\
\hline C. dewulfi & 46 & 0.44 & 0.43 & $1.00^{2}$ & 0.25 & 0.45 & 0.45 & 1.00 & 0.24 \\
\hline C. scoticus & 27 & 0.12 & 0.40 & 0.25 & 0.00 & 0.12 & 0.40 & 0.25 & 0.00 \\
\hline C. punctatus & 16 & 0.50 & - & 1.00 & 0.54 & 0.50 & - & 1.00 & 0.54 \\
\hline
\end{tabular}

${ }^{1}$ Different letters mean difference between traps in predicted number of females for $\alpha=0.05$

${ }^{2}$ Only C. dewulfi parous female was collected with the sticky cover trap sheep and exceed the abundance of other commonly found Culicoides implicated in BTV within this region. In northern Europe, the most common species collected on livestock belong to the subgenus Avaritia: C. obsoletus and C. dewulfi on cattle [8,10], C. obsoletus on horses $[9,11]$ and $C$. obsoletus and $C$. chiopterus on sheep [12]. All these species are suspected to be BTV8 vectors due to i) their abundance and their ability to bite ruminants, notably in absence of C. imicola [28], ii) the identification of BTV from field-collected individuals [29-31] and iii) for $C$. obsoletus and C. scoticus, their ability to be infected with BTV $[5,32,33]$. Culicoides brunnicans breeding sites are not clearly identified [34] but could include grasslands and, to a lesser extent, forests and wet areas (Delécolle, unpublished data). The high abundance of $C$. brunnicans may be related to the surrounding environment, which consisted primarily of pastures favorable to the species. Culicoides brunnicans is described as widely distributed in the western Palaeartic region [34]. Based on the French vector surveillance network, this species was collected in 73 out of 160 sites throughout the country. In these sites its abundance is usually very low: (1\% of the total catch only in 23 sites) but locally abundant with an abundance reaching 10 to $13 \%$ of the total collection [35]. Little attention, however, has been paid to this species with respect to BTV transmission, despite its possible local abundance [36].

The risk of virus transmission is dependent, amongst other factors, on both biting rate and parity rate, a rough indicator of population survival [37-39]. Therefore, accurate and unbiased estimates of these parameters are essential for epidemiological modeling. However, collecting biting midges on animals is challenging, and Culicoides abundance may vary greatly between habitats [40]. In a given environment, flight activity will be greatly impacted by daily meteorological conditions, especially temperature, air humidity, light intensity or wind speed [12]. Moreover, host-seeking female distribution could be structured at a very fine scale [41], due to influence of host presence and abundance [42], or nearby environment [43,44]. Indeed, site 2 recorded the highest abundance of C. brunnicans probably because it was the nearest trap to the grazing sheep herd. For other, less abundant Culicoides species, the use of a single animal to bait traps may have limited the number of Culicoides caught [42]. Finally, observed parity rates were all rather high. It could mean that collections occurred at the end of the spring Culicoides activity peak and before the start of summer emergence of most species. This may lead to the low abundance recorded even if collections were carried out in temperature ranges compatible with Culicoides activity [45].

Direct aspiration was the only collection method which did not collect male or gravid females, suggesting 


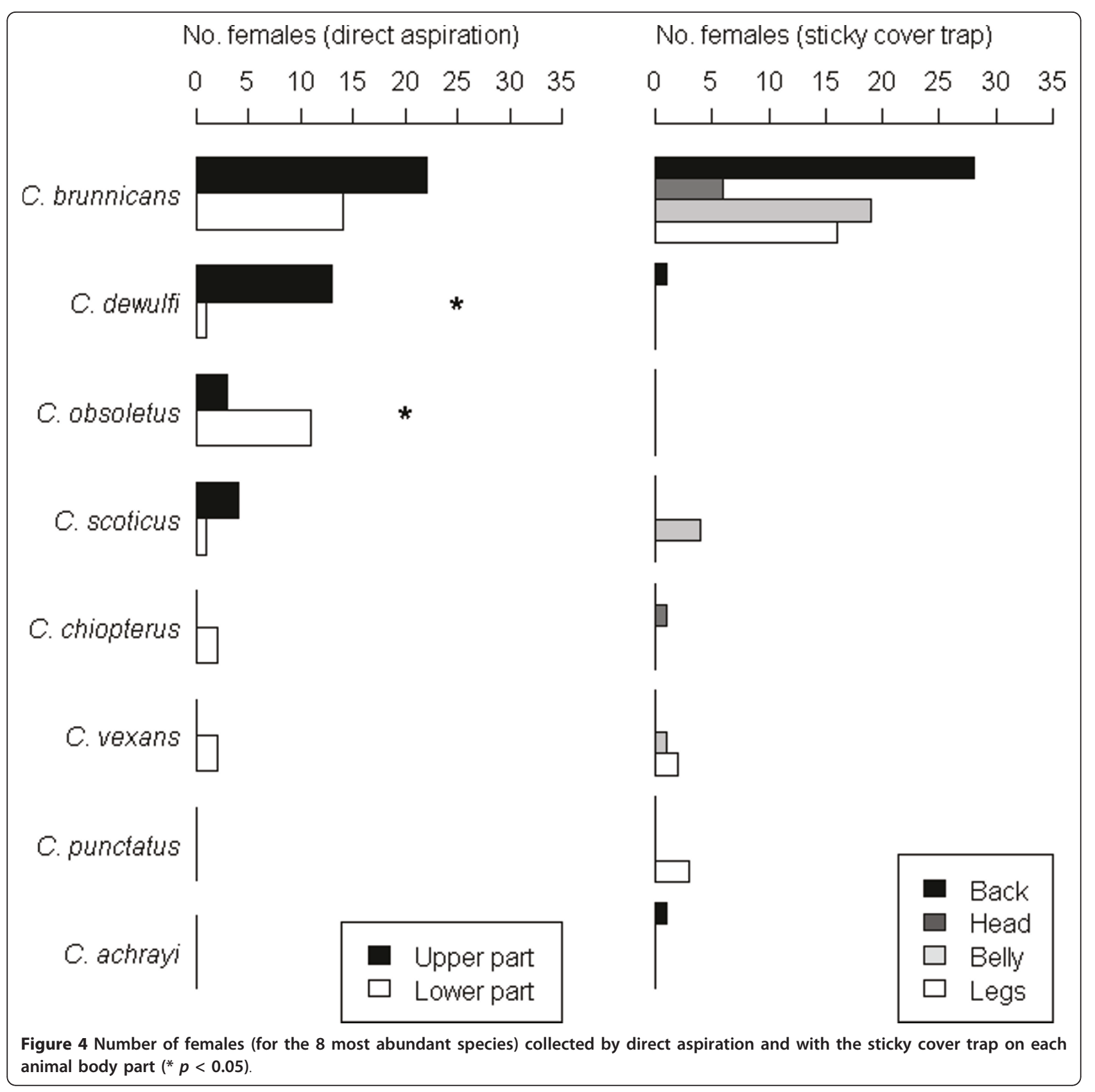

that only host-seeking females were collected. This method collected fewer or equivalent numbers of females versus other host-baited traps, suggesting that human presence and activity during $10 \mathrm{~min}$ of aspiration may disturb host-seeking activity. Except for C. scoticus, the drop trap was the host-baited trap which collected the highest number of females. There were few males in the collections (due to the drop trap sampling air space near the host). This drop trap therefore does not strictly collect only host-seeking females, although they are most likely dominant among Culicoides collected in the vicinity of the host. There was also a higher proportion of parous C. obsoletus females compared to other traps. It is possible that the visual aspects of the drop trap (tall trap structure and the large white surface of the net) may have some effects. For instance, male swarm occurred more or less directly above an object contrasting strongly in color and brightness with the background [46]. This may lead to a possible bias in estimating the biting rate. One advantage of the drop trap is the possibility for Culicoides to feed quite naturally on animal bait. No $C$. dewulfi females were found 

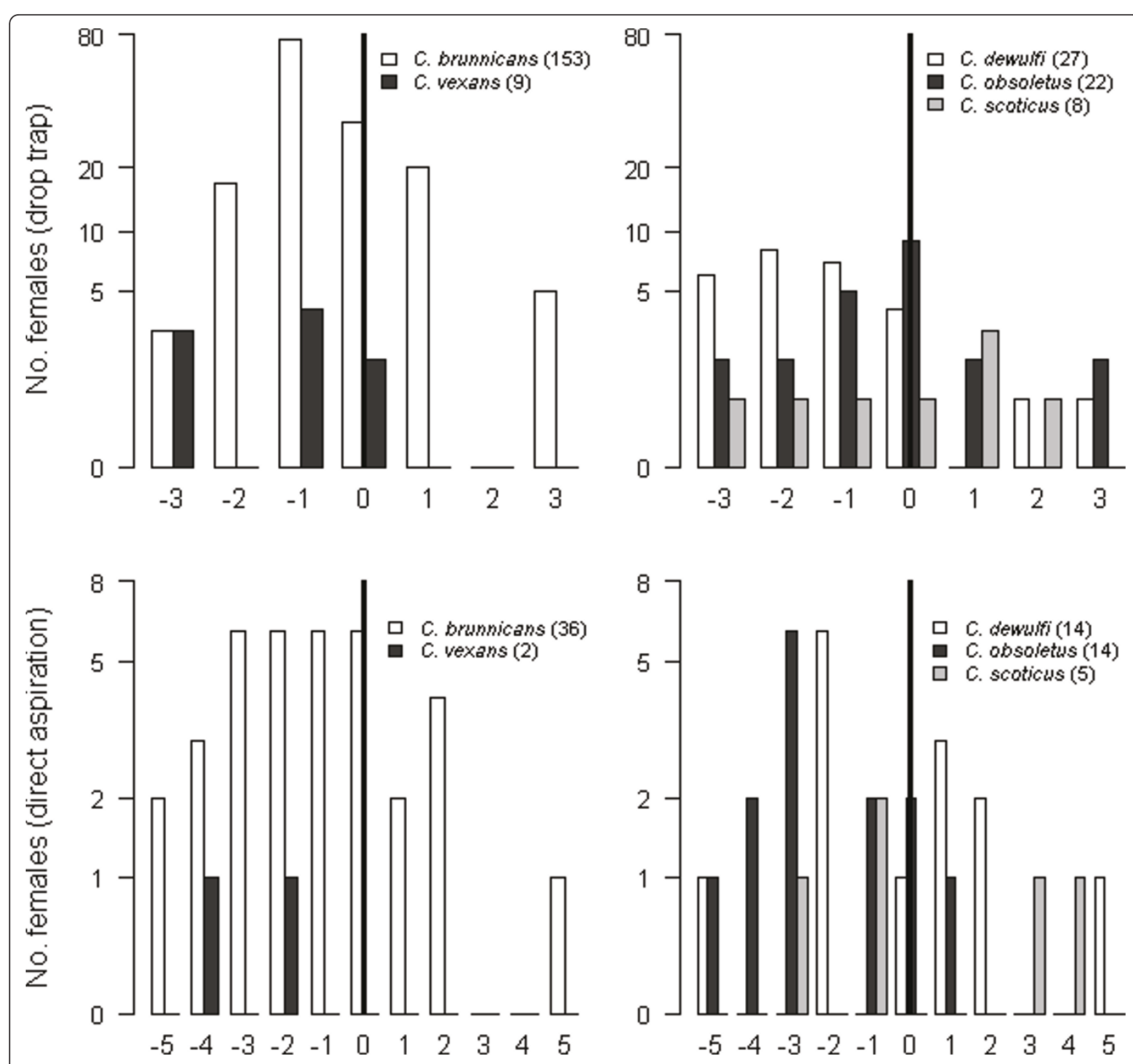

Figure 5 Number of females (for the 5 most abundant species) collected by direct aspiration and with the drop trap each time period (20 min for DA and $30 \mathrm{~min}$ for DT) around the sunset (represented by thick line).

engorged on sheep, suggesting that this species might be attracted by sheep without feeding on them. The same behavior was suggested recently for C. chiopterus [19], both species being recognized to be strongly associated with cattle [47]. The sticky cover trap collected the same abundance and parity rate of C. brunnicans than the drop trap, thus suggesting that this trap was efficient to estimate biting rate for dominant species, even if presence of gravid or engorged females may suggest that it could act as an interception trap. Surprisingly, the sticky cover trap did not collect any C. obsoletus and only one C. dewulfi. These species could attack animal parts which were not sufficiently covered by the sticky cover (i.e. head, ears). However, we cannot exclude a repellent effect of the petroleum jelly to these species, even if it is probable that Culicoides could not detect the gel before entering into contact because this product does not evaporate. This trap may be improved by a better design and by using another sticky substance easier to handle than petroleum jelly.

In our study, the UV-light/suction trap under-estimated the C. brunnicans biting rates, whereas it seemed to over-estimate $C$. obsoletus biting rates as recorded by Carpenter et al. [12]. It can be in contradiction to Gerry et al. [13] who collected fewer C. obsoletus females in the UV-light/suction trap than on sheep but these 
apparently contradictory findings might be explained by the very high suction rate (air flow) of the OVI relative to the CDC-type traps used by Gerry et al. $[13,14]$. This trap remains an efficient and practical tool to describe species richness in an area, but presence of males, gravid females and single specimens of species which were not collected by host-baited traps suggested that this method did not only collect host-seeking females in the UV-light/suction trap. This could undermine the assessment of BTV risk as UV-light/suction traps have been used in national surveillance networks since 2000 in south Europe and since 2008 in north and central of Europe, most Culicoides survey were done using UVlight/suction traps [28,48-51].

Collections by direct aspiration and sticky cover trap highlighted that C. brunnicans attacked all parts of the animal, whereas $C$. obsoletus seemed to attack preferentially lower parts and $C$. dewulfi the upper parts. Nielsen [8] found the same behavior for C. obsoletus, with nearly all individuals collected from the belly of heifers, whereas C. chiopterus attacked preferentially the legs. On the contrary, Townley [9], who explored the preferential landing and feeding sites of Culicoides on horses in Ireland, observed that the most abundant species, $C$. obsoletus and $C$. dewulfi, did not seem to have preferential landing sites whereas C. punctatus, Culicoides nubeculosus (Meigen) and Culicoides pulicaris (Linnaeus) fed at the predilection sites of sweet itch. Preferential landing sites may differ for a same Culicoides species depending on the host, due to variations in hair wool density, colors and skin temperatures according to the host body parts [52].

For the first time in Europe, this study compares the ability of multiple types of host-baited traps to collect host-seeking females compared to UV-light/suction traps. We observed bias of each trapping method through Culicoides sampling, which highlight the relevance of each trap for different kinds of Culicoides ecology studies. Direct aspiration seemed to collect only host-seeking females and can be used to assess accurately Culicoides biting rate even if the possible disturbance of host-seeking females due to human manipulation is not clear. The sticky cover trap showed its ability to assess biting rates of abundant species. After improvements (better design of the cover or sticky substance easier to use), this method has promise to conduct easily (without human intervention) host-baited collections even if we do not have an explanation of the $C$. obsoletus absence in collections. The drop trap resulted in higher estimated Culicoides biting rates or numbers (including presence of males in collections, high abundance for most host-biting species). Most importantly, the main advantage of the DT is that it allows assessing the engorgement level of insects and then highlighted singular behavior as for $C$. dewulfi, which seems attracted to sheep but unwilling to feed on them. The UV-light/suction trap is the most effective method to collect large numbers of Culicoides midges, for example to carry out biological studies involving live Culicoides midges in the absence of a colony, because it remains the easiest to use maximizing diversity in collections. However, UV-light/suction traps abundances cannot be used directly to assess Culicoides biting rates. Given possible environmental influences on Culicoides species behaviors, this study should be repeated in other ecosystems hosting other species and/or other hosts (horses, cattle) and in different climatic conditions to obtain a better understanding of the relation between biting rates and UV-light/suction trap collections. This is of significant importance for the assessment of BTV risk throughout Europe.

\section{Acknowledgements}

We are particularly grateful to the co-operators on whose premises this work was conducted. From the Plateforme d'infectiologie expérimentale (PFIE) Inra Nouzilly, we would like to thank its director B. Schwartz, and all people who gave assistance in operating traps on several nights (technicians, animal keepers, shepherds), especially P. Sarradin for his involvement in this project. This study was funded partly by CIRAD and partly by the Ministry of Agriculture, Food, Fishing and Rural Affairs. We thank Hélène Guis (Cirad) for reading and commenting the manuscript and three anonymous reviewers who helped us to improve this paper.

\section{Author details}

${ }^{1}$ CIRAD, UMR Contrôle des maladies, F-34398 Montpellier, France. ${ }^{2}$ INRA, UE1277 PFIE, Plate Forme d'Infectiologie Expérimentale, F-37380 Nouzilly, France. ${ }^{3}$ UdS, IPPTS, Faculté de Médecine, F-67000 Strasbourg, France. ${ }^{4}$ Université de Montpellier 2, ISEM équipe «Interactions », F-34000 Montpellier, France.

\section{Authors' contributions}

$E V, C G$ and $T B$ designed the study. EV, CG, TB, XA, LG, IR and DC carried out the experimentations. $E V, R L$ and $T B$ analyzed the data. $E V$ and $T B$ wrote the manuscript, which was revised by CG, TB, CM, and RL. All authors read and approved the final manuscript.

\section{Competing interests}

The authors declare that they have no competing interests.

Received: 15 April 2011 Accepted: 27 June 2011

Published: 27 June 2011

\section{References}

1. Mellor PS, Boorman J, Baylis M: Culicoides biting midges: Their role as arbovirus vectors. Annu Rev Entomol 2000, 45:307-340.

2. Mellor PS, Carpenter S, Harrup L, Baylis M, Mertens PPC: Bluetongue in Europe and the Mediterranean Basin: History of occurrence prior to 2006. Prev Vet Med 2008, 87:4-20.

3. Mellor PS, Carpenter S, Harrup L, Baylis M, Wilson A, Mertens PPC: Bluetongue in Europe and the Mediterranean Basin. In Bluetongue. Edited by: Mellor PS, Baylis M. Mertens PPC: Elsevier; 2009:235-264.

4. Velthuis AGJ, Saatkamp HW, Mourits MCM, de Koeijer AA, Elbers ARW: Financial consequences of the Dutch bluetongue serotype 8 epidemics of 2006 and 2007. Prev Vet Med 2010, 93:294-304.

5. Mellor PS, Carpenter S, White DM: Bluetongue virus in the insect host. In Bluetongue. Edited by: Mellor PS, Baylis M, Mertens PPC. Elsevier; 2009:295-320.

6. Silver JB, Service MW: Sampling adults by animal bait catches and by animal-baited traps. Mosquito ecology field sampling methods Dordrecht, the Netherlands: Springer; 2008, 493-675. 
7. Garrett-Jones C: Prognosis for interruption of malaria transmission through assessment of the mosquito's vectorial capacity. Nature 1964, 204:1173-1175.

8. Overgaard Nielsen B: Some observations on biting midges (Diptera: Ceratopogonidae) attacking grazing cattle in Denmark. Entomol Scand 1971, 2:94-98

9. Townley P, Baker KP, Quinn PJ: Preferential landing and engorging sites of Culicoides species landing on a horse in Ireland. Equine Vet J 1984, 16:117-120.

10. Olbrich $S$, Liebisch $A$ : Untersuchungen zum vorkommen und zum befall mit gnitzen (Diptera: Ceratopogonidqe) bei weiderindern in Norddeutschland. Mitt Dtsch Ges Allg Angew Entomol 1988, 6:415-420.

11. van der Rijt $R$, van den Boom $R$, Jongema $Y$, van OldruitenborghOosterbaan MM: Culicoides species attracted to horses with and without insect hypersensitivity. Vet J 2008, 178:91-97.

12. Carpenter S, Szmaragd C, Barber J, Labuschagne K, Gubbins S, Mellor P: An assessment of Culicoides surveillance techniques in northern Europe: have we underestimated a potential bluetongue virus vector? I Appl Ecol 2008, 45:1237-1245.

13. Gerry AC, Monteys VSI, Vidal JOM, Francino O, Mullens BA: Biting rates of Culicoides midges (Diptera: Ceratopogonidae) on sheep in northeastern spain in relation to midge capture using UV light and carbon dioxidebaited traps. J Med Entomol 2009, 46:615-624.

14. Venter GJ, Labuschagne K, Hermanides KG, Boikanyo SNB, Majatladi DM, Morey L: Comparison of the efficiency of five suction light traps under field conditions in South Africa for the collection of Culicoides species. Vet Parasitol 2009, 166:299-307.

15. Delécolle J-C: Nouvelle contribution à l'étude systématique et iconographique des espèces du genre Culicoides (Diptera:

Ceratopogonidae) du Nord-Est de la France. Thèse de Doctorat d'Université mention Sciences Université Louis Pasteur; 1985.

16. Dyce AL: The recognition of nulliparous and parous Culicoides (Diptera: Ceratopogonidae) without dissection. J Aust Entomo/ Soc 1969, 8:11-15.

17. Nolan DV, Carpenter S, Barber J, Mellor PS, Dallas JF, Mordue AJ, Piertney SB: Rapid diagnostic PCR assays for members of the Culicoides obsoletus and Culicoides pulicaris species complexes, implicated vectors of bluetongue virus in Europe. Vet Microbiol 2007, 124:82-94.

18. Solano P, Duvallet G, Dumas V, Cuisance D, Cuny G: Microsatellite markers for genetic population studies in Glossina palpalis (Diptera: Glossinidae). Acta Trop 1997, 65:175-180.

19. Garros C, Gardès L, Allène X, Rakotoarivony I, Viennet E, Rossi S, Balenghien T: Development of an allele-specific multiplex PCR assay for the identification of blood meal source in Culicoides (Ceratopogonidae: Diptera). Applications on Palaearctic biting midge species. Infect Genet Evol 2011, 11:1103-1110.

20. McCullagh P, Nelder JA, (Eds): Generalized Linear Models., Second 1989, London.

21. Ridout M, Demétrio CGB, Hinde J: Models for count data with many zeros. International Biometric Conference; Cape Town 1998.

22. Zeileis A, Kleiber C, Jackman S: Regression models for count data in R. $J$ Stat Softw 2008, 27.

23. Cook RD: Influential observations in linear regression. J Am Stat Assoc 1979, 74:169-174.

24. Hauck WW, Donner A: Wald's test as applied to hypotheses in logit analysis. JAMA 1977, 82:1110-1117.

25. Goldstein H, Healy MJR: The Graphical Presentation of a Collection of Means. J Roy Stat Soc a Sta 1995, 158:175-177.

26. R: A language and environment for statistical computing. [http://cran.rproject.org/manuals.html].

27. Venables WN, Ripley BD: Modern applied statistics with S 2002

28. Meiswinkel R, Baldet T, de Deken R, Takken W, Delecolle JC, Mellor PS: The 2006 outbreak of bluetongue in northern Europe - The entomological perspective. Prev Vet Med 2008, 87:55-63.

29. Meiswinkel R, van Rijn P, Leijs P, Goffredo M: Potential new Culicoides vector of bluetongue virus in northern Europe. Vet Rec 2007, 161:564-565.

30. Dijkstra E, van der Ven IJK, Melswinkel R, Holzel DR, van Rijn PA, Meiswinkel R: Culicoides chiopterus as a potential vector of bluetongue virus in Europe. Vet Rec 2008, 162:424-424.

31. Hoffmann B, Bauer B, Bauer C, Batza HJ, Beer M, Clausen PH, Geier M, Gethmann JM, Kiel E, Liebisch G, et al: Monitoring of Putative Vectors of
Bluetongue Virus Serotype 8, Germany. Emerg Infect Dis 2009, 15:1481-1484

32. Carpenter S, Lunt HL, Arav D, Venter GJ, Mellor PS: Oral susceptibility to bluetongue virus of Culicoides (Diptera: Ceratopogonidae) from the United Kingdom. J Med Entomol 2006, 43:73-78.

33. Carpenter S, McArthur C, Selby R, Ward R, Nolan DV, Luntz AJM, Dallas JF, Tripet F, Mellor PS: Experimental infection studies of UK Culicoides species midges with bluetongue virus serotypes 8 and 9. Vet Rec 2008, 163:589-592.

34. Sarto i Monteys V, Delecolle JC, Moreno-Vidal JO, Pinna M: New Records of Biting Midges of the Genus Culicoides Latreille (Diptera:

Ceratopogonidae) for Spain and Catalonia Autonomous Community ( $\mathrm{Ne}$ Spain), with Notes on Their Biology and Veterinary Importance. Proc Entomol Soc Wash 2009, 111:714-733.

35. Balenghien $T$, Garros C, Mathieu B, SRM L, Allène X, Gardès L, Rakotoarivony I, Venail R, Akaddar A, Drouet $M$, et al: La surveillance des Culicoides en France. Bulletin épidémiologique 2010, 35:8-9.

36. Jennings DM, Mellor PS: The vector potential of British Culicoides species for bluetongue virus. Vet Microbiol 1988, 17:1-10.

37. Macdonald G: The analysis of infection rates in diseases in which superinfection occurs. Trop Dis Bull 1950, 47:907-915.

38. Garrett-Jones C, Shidrawi GR: Malaria vectorial capacity of a population of Anopheles gambiae. An exercise in epidemiological entomology. Bull World Health Organ 1969, 40:531-545.

39. Service MW: A critical review of procedures for sampling populations of adult mosquitoes. Bull Entomol Res 1977, 67:343-382.

40. Bishop AL, McKenzie J, Spohr $\amalg$, Barchia IM: Culicoides brevitarsis Kieffer (Diptera: Ceratopogonidae) in different farm habitats. Aust J Zool 1994, 42:372-384.

41. Murray MD: Local dispersal of the biting midge Culicoides brevitarsis Kieffer (Diptera: Ceratopogonidae) in south-eastern Australia. Aust J Zool 1987, 35:559-573.

42. Garcia-Saenz A, McCarter P, Baylis M: The influence of host number on the attraction of biting midges, Culicoides spp., to light traps. Med Vet Entomol 2011, 25:113-115.

43. Barnard BJH: Some factors governing the entry of Culicoides spp. (Diptera: Ceratopogonidae) into stables. Onderstepoort J Vet 1997. 64:227-233.

44. Baylis M, Parkin H, Kreppel K, Carpenter S, Mellor PS, Mclntyre KM: Evaluation of housing as a means to protect cattle from Culicoides biting midges, the vectors of bluetongue virus. Med Vet Entomol 2010, 24:38-45.

45. European Food Safety Authority EFSA: Bluetongue Scientific Opinion of the Panel on Animal Health and Welfare (Question No EFSA-Q-2007-201) adopted on 19 June 2008. The EFSA Journal 2008, 735:1-70.

46. Downes JA: Observations on the swarming flight and mating of Culicoides (Diptera: Ceratopogonidae). Transactions of the Royal Entomological Society of London 1955, 106:213-236.

47. European Food Safety Authority E: Bluetongue Scientific Opinion of the Panel on Animal Health and Welfare (Question No EFSA-Q-2007-201) adopted on 19 June 2008. The EFSA Journal 2008, 735:1-70.

48. Calistri P, Goffredo M, Caporale V, Meiswinkel R: The distribution of Culicoides imicola in Italy: Application and evaluation of current Mediterranean models based on climate. J Vet Med B 2003, 50:132-138.

49. Conte A, Goffredo M, Ippoliti C, Meiswinkel R: Influence of biotic and abiotic factors on the distribution and abundance of Culicoides imicola and the Obsoletus Complex in Italy. Vet Parasitol 2007, 150:333-344.

50. Baldet T, Delécolle JC, Cetre-Sossah C, Mathieu B, Meiswinkel R, Gerbier G: Indoor activity of Culicoides associated with livestock in the bluetongue virus (BTV) affected region of Northern France during autumn 2006. Prev Vet Med 2008, 87:84-97.

51. Mehlhorn H, Walldorf V, Klimpel S, Schaub G, Kiel E, Focke R, Liebisch G, Liebisch A, Werner D, Bauer C, et al: Bluetongue disease in Germany (2007-2008): monitoring of entomological aspects. Parasitol Res 2009, 105:313-319.

52. Braverman Y: Preferred landing sites of Culicoides species (Diptera: (eratopogonidae) on a horse in Israel and its relevance to summer seasonal recurrent dermatitis (sweet itch). Equine Vet J 1988, 20:426-429.

doi:10.1186/1756-3305-4-119

Cite this article as: Viennet et al:: Assessment of vector/host contact: comparison of animal-baited traps and UV-light/suction trap for collecting Culicoides biting midges (Diptera: Ceratopogonidae), vectors of Orbiviruses. Parasites \& Vectors 2011 4:119. 